\title{
Ingested Pin Causing Acute Appendicitis In A Child
}

\author{
Sudhir Singh, ${ }^{*}$ Nitin Pant, JD Rawat
}

Department of Pediatric Surgery, King George's Medical University, Lucknow, India.

\section{ABSTRACT}

Ingested foreign body (FB) can occasionally lodge into the vermiform appendix leading to its inflammation. A 4year-old girl presented with features of acute appendicitis. On $X$ ray abdomen a metallic pin was seen in right lower abdomen. Patient had open appendicectomy and a metallic pin was found penetrating both walls of appendix near its tip. Postoperative recovery was uneventful.

\section{Key words: Foreign body ingestion; Appendicitis; Child}

Correspondence*: Dr Sudhir Singh, Department of Pediatric Surgery, King George's Medical University (KGMU) Lucknow, India.

E-mail: drsudhir_singh25@yahoo.in_ (C) 2017, Singh et al.

Submitted: 14-06-2017

Accepted: 18-06-2017

Conflict of Interest: None

Source of Support: Nil

This is an open-access article distributed under the terms of the Creative Commons Attribution License, which permits unrestricted use, distribution, and reproduction in any medium, provided the original work is properly cited.

\section{INTRODUCTION}

Acute appendicitis due to FB ingestion is very rare.[1-3] Bones, nails, stones, seeds of fruits and vegetables, and air gun pellets, have been described lodging into the appendix lumen. We present here a four year-old girl with metallic pin ingestion leading to acute appendicitis.

\section{CASE REPORT}

A 4-year-old girl child presented with lower abdominal pain, vomiting, fever, and abdominal distension for five days. On abdominal radiograph, a radiopaque foreign body was identified in a right lower abdomen along with few air-fluid levels (Fig.1A).

At operation, acutely inflamed appendix perforated at its tip by a metallic needle (Fig.1B), which had penetrated both walls of appendix, with omental adhesion, was found (Fig.2A,B).

Postoperative course remained uneventful. Histopathology of removed appendix showed inflammatory changes.

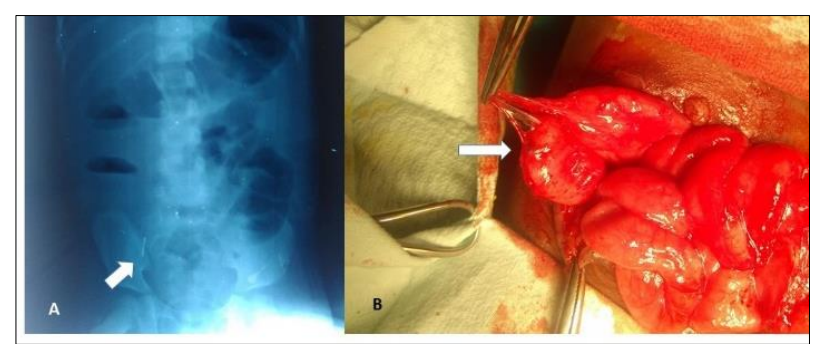

Figure 1: A. Plane $\mathrm{X}$ ray abdomen showing a radiopaque foreign body (marked by arrow) in right lower abdomen. B. Intraoperative picture showing inflamed appendix with metallic pin visible (marked by arrow) near tip.

\section{DISCUSSION}

The ingestion of foreign bodies is a frequent occurrence, especially among children. Majority of these objects pass out safely through the gastrointestinal tract, without causing any symptoms. However, in $1 \%$ of cases, ingested FB can result in complications such as intestinal perforation, intestinal obstruction, fistula formation, and appendicitis.[4] On rare occasions, ingested FBs make their way into the appendix and are not able to reenter the 
normal gastrointestinal tract. Appendicitis due to foreign bodies is rare with $n$ incidence of $0.005 \%$.[3]

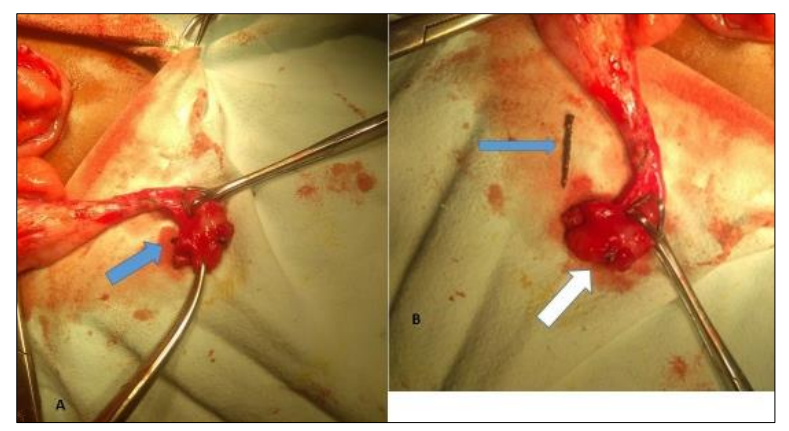

Figure 2: A. Intraoperative picture showing metallic pin visible on both side of appendix (marked by arrow) near tip. B. Intraoperative picture showing metallic pin (marked by blue arrow) and site of appendix where pin was entrapped (marked by white arrow).

In our patient the exact duration of ingestion of needle was not known, though the baby presented with a short history of abdominal symptoms. Intraoperatively, the rusted pin was found penetrating the appendicular wall on both sides near tip and lying transversely.
Consent: Authors have submitted signed consent form from legal guardians of the patient for use of clinical material in this manuscript. The Consent form is available with Editorial office.

Authors' Contribution: All authors contributed equally in concept, literature review, and drafting of the manuscript and approved the final version of this manuscript.

\section{REFERENCES}

1. Sinha DD, Sharma C, Gupta V, Chaturvedi V. Sewing needle appendicitis in a child. Indian J Gasroenterol. 2004; 23:219-20.

2. Losanoff JE, Jones JW, Richner OW. Acute appendicitis resulting from intraluminal shotgun pellets. ANZ J Surg. 2002; 72:168.

3. Sukhotnik I, Klin B, Siplovich L. Foreign body appendicitis. J Pediatr Surg. 1995; 30:1515-6.

4. Ngom G, Amadou I, Ngaringuem O, Ndour O. 'PEN' appendicitis. J Indian Assoc Pediatr Surg. 2010; 15:74-5. 